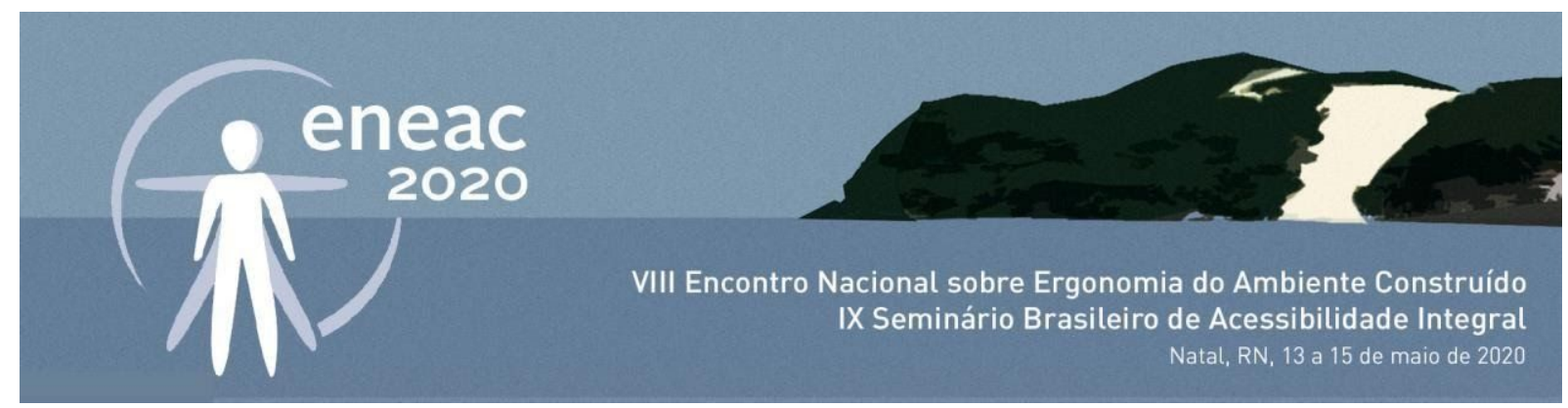

\title{
Universalização da acessibilidade à cultura e à arte: um estudo de caso sobre o Porto Dragão
}

\author{
Universalization of accessibility to culture and art: a case study \\ about Porto Dragão
}

\author{
BÁRBARA DUARTE \\ JOÃO MARCELLO TORQUATO \\ KELVE FREITAS \\ ZILSA MARIA SANTIAGO
}

\section{RESUMO}

O presente artigo tem como objetivo fazer uma breve reflexão acerca das condições de acessibilidade em equipamentos culturais, tomando como estudo de caso o Porto Dragão - um recente equipamento, que compõe o pólo de cultura e arte, localizado no bairro Praia de Iracema, em Fortaleza. Inicialmente, o objetivo surgiu de uma demanda real de adequação de acessibilidade do Porto Dragão, no intuito de democratizar e universalizar o acesso à cultura e à arte em suas atividades. Para além disso, decidiu-se, dentro de uma metodologia indutiva, seguir com estudos para situar a demanda em um contexto mais amplo de inadequação desses espaços no que tange a necessidade de acesso dos mais diferentes públicos. Por meio da revisão bibliográfica sobre o que envolve o significado de acessibilidade e posterior visita a campo buscou-se analisar as condições espaciais desse edifício e, a partir disso, propor soluções e um conjunto de diretrizes para intervenções em sua dimensão arquitetônica. PALAVRAS-CHAVE: Acessibilidade, Arte, Cultura, Arquitetura.

\section{ABSTRACT}

The present article has as its objective make a short reflection about the accessibility conditions of cultural buildings, taking how study case the Porto Dragão - a recent edifice that compose the city culture and art scene, located in the Praia de Iracema neighborhood. Initially, the objective arised from a Porto Dragão real demand for accessibility adequation, in order to democratize and universalize the access of the culture and art in its activities. Furthermore, was decided, based on a inductive methodology, continue with the studies to situate the demand in a broader context of inadequation of these spaces, regarding the necessity for access by the most different publics. Through the literature review, about the several meanings of the accessibility and later visit on the spot, sought to analyze the space conditions of this building, and after, to propose solutions and a set of guidelines to interventions in its architectural dimension. KEYWORDS: Accessibility, Art, Culture, Architecture. 


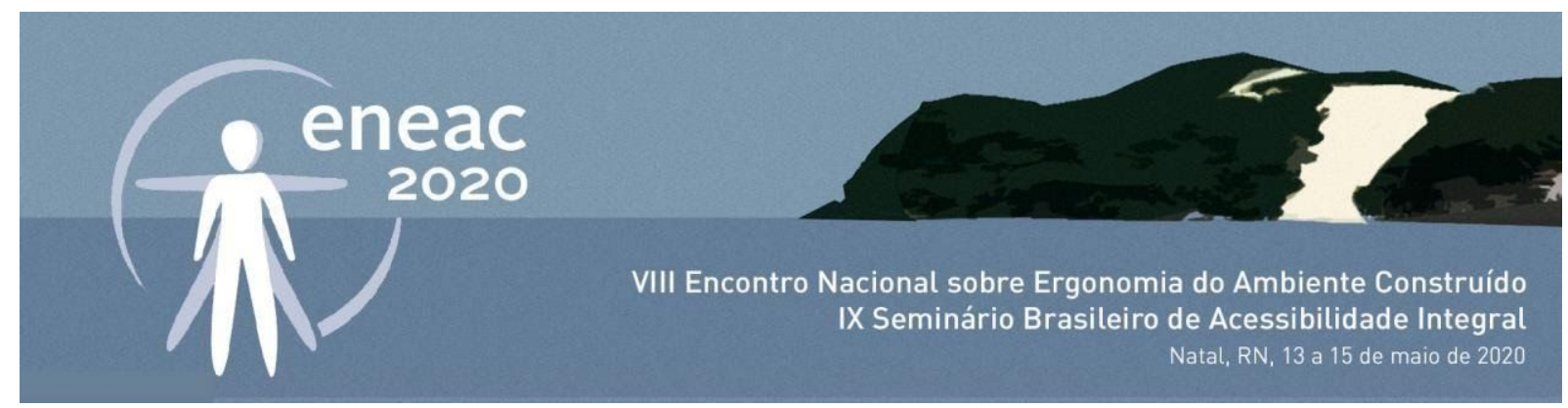

\section{INTRODUÇÃO}

Depois de um longo histórico de dificuldades enfrentado por aqueles que se encontram fora da ideia do corpo padrão com relação a usufruir de um espaço genérico, hoje, é adotada como responsabilidade coletiva conceber e adaptar ambientes que contemplem o universal, pois esse é o caminho para garantir a todos o direito de ocupar o espaço. Tal mudança de paradigma é essencial para o objetivo de universalizar o acesso à educação, à saúde, ao lazer e à cultura. É de grande importância que haja um comprometimento social e valorização do desenho universal como elemento indispensável para a promoção da acessibilidade, almejando um alinhamento entre o discurso idealizado e sua concretização.

O Porto Dragão apresentou-se como uma demanda real dentro dessa temática, com certa urgência de execução uma vez que comprometeu-se em sediar o II Seminário Cultura do Acesso. Esse, mesmo sendo um equipamento de uso "recente", não é uma construção nova, é um reuso de galpões da antiga área de armazéns do Porto, daí vem a origem do nome. Neste sentido, admite-se possuir um baixo grau de desenho universal. Diante disso, a primeira tarefa constituiu-se na elaboração de um diagnóstico das áreas de uso público para, então, gerar insumos para propostas e diretrizes que guiarão adequações e mudanças necessárias na edificação. $\mathrm{O}$ embasamento teórico estabelece um cenário para a temática abordada neste trabalho e, também, reforça o pensamento crítico referente à acessibilidade permeando o meio físico e a arte.

\section{METODOLOGIA}

Alguns estudos foram importantes na fundamentação teórico-metodológica (Preiser, 2001; Sassaki, 2003; Rheingantz et al, 2009; Ornstein et al, 2010; Dischinger et al, 2012; Santiago, 2013); além da legislação e normas (NBR 9050/2015; NBR 16537:2016; Decreto 5.296/2004; Lei 13.146/2015).

Utilizou-se como metodologia a Avaliação Pós-Ocupação - APO (ORNSTEIN, 1992), onde tomou-se como ponto de partida a análise espacial do Porto Dragão para uma investigação do grau de acessibilidade de seus espaços sob considerações da democratização das artes nesse Polo Cultural da Praia de Iracema.

Como ferramentas utilizadas, configuram-se visita in loco e o Walkthrough (RHEINGANTZ et al., 2009) e a avaliação física, a partir de levantamentos métricos e registros fotográficos de "ambientes-chaves" com base em checklist para adequação do Porto Dragão às normas de acessibilidade. Em paralelo, foram consultadas as normas NBR 9050:2015 e a NBR 16537:2016, bem como outras bibliografias referentes à universalização da cultura e da arte em equipamentos urbanos (CUTY; COUTO, 2014; SANTOS, 2009; SARRAF, 2018). 


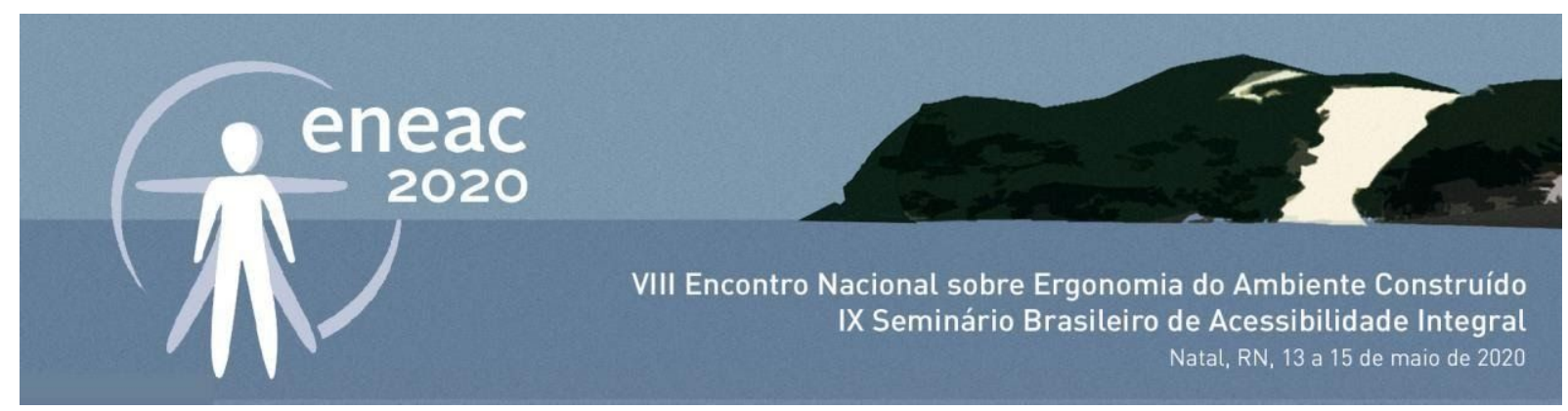

\section{ESFERAS DE ACESSIBILIDADE}

Segundo Santos Filho (2010), apesar das normas serem elaboradas por um consenso entre partes envolvidas, alguns requisitos são necessários para que sejam efetivamente implementadas, tais como: qualidade técnica, interesse de usuários e da sociedade em geral, respaldo de grupos econômicos e do poder público. A combinação desses quesitos resulta no grande progresso da normatização brasileira, contudo, a falta de cumprimento normativo ocasionado pela pouca fiscalização e falta de uma cultura de inclusão, tornam esses requisitos inexequíveis, ficando evidente a não operacionalização das normas em relação ao ambiente construído, o que gera consequências no cotidiano das pessoas com deficiência. Diversas iniciativas pontuais, que merecem reconhecimento, foram observadas, porém poucas são as cidades brasileiras em que se encontre a acessibilidade de forma significativa. A acessibilidade extrapola a dimensão técnica e passa a simbolizar um conjunto de direitos e de qualidade de vida indispensável no desenvolvimento da pessoa com deficiência (SARRAF, 2018). Nesse sentido, a Lei Brasileira de Inclusão, de 2015, propõe uma nova definição para o conceito, quando diz que: "Acessibilidade é o direito que garante à pessoa com deficiência viver de forma independente e exercer seus direitos de cidadania e de participação social" (LBI, 2015, artigo 53).

De acordo com Dischinger e Bins Ely (2005), o termo acessibilidade é de grande abrangência e não está ligado à apenas fatores físicos-espaciais como deslocamento e conforto, mas sim, às questões políticas, sociais e culturais. Dischinger, Bins Ely e Piardi (2011), consideram a "acessibilidade espacial significa bem mais do que poder atingir um lugar desejado". As autoras criaram quatro componentes para acessibilidade: orientação - deslocamento - comunicação uso.

A acessibilidade está ligada às práticas de inclusão e visa abranger todos os espectros da diversidade. Para isso, é necessário que se garanta a possibilidade de livre acesso aos mais diversos locais e dinâmicas, a fim de eliminar barreiras. Dentre elas, as principais configuram-se como barreiras atitudinais, que podem ser entendidas como os preconceitos sociais existentes contra um indivíduo ou um grupo e em como tais preconceitos podem ser refletidos em atitudes para com o diferente.

A criação de espaços com ausência de barreiras torna-se uma necessidade para garantir universalização da cidadania (SANTIAGO; NASCIMENTO, 2014), visto que os espaços públicos, muitas vezes, são considerados inadequados ao atendimento das necessidades básicas de acesso e, por conta disso, comprometem sensivelmente a qualidade de vida e equidade social. É preciso pensar e construir uma cultura inclusiva para ser disseminada em todos os setores da vida citadina (Figura 1). Para este artigo, o foco é a acessibilidade espacial como fator de inclusão na cultura, nos equipamentos culturais. 


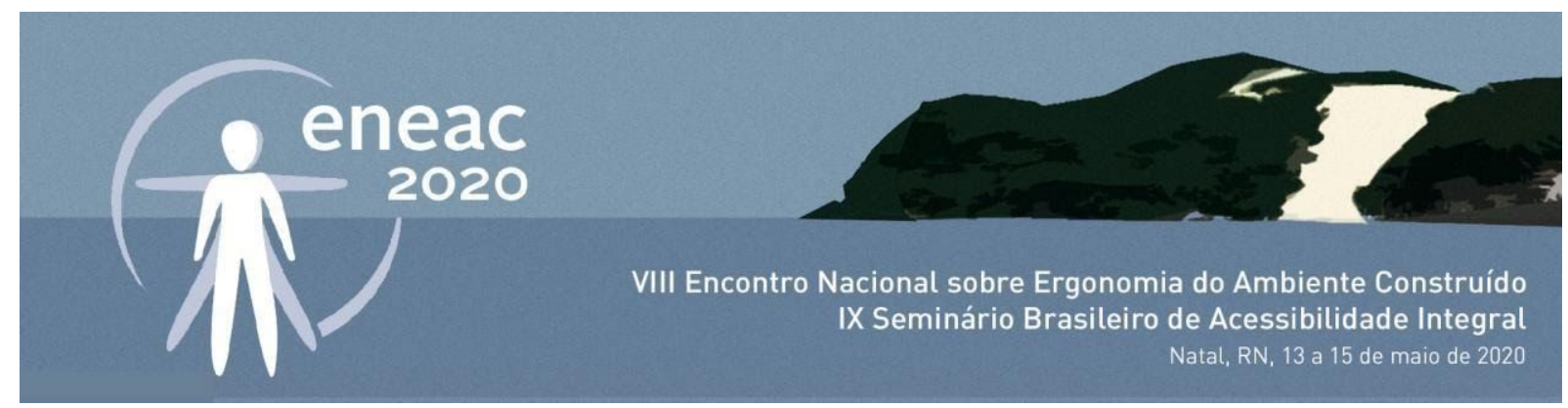

Figura 1: Diagrama

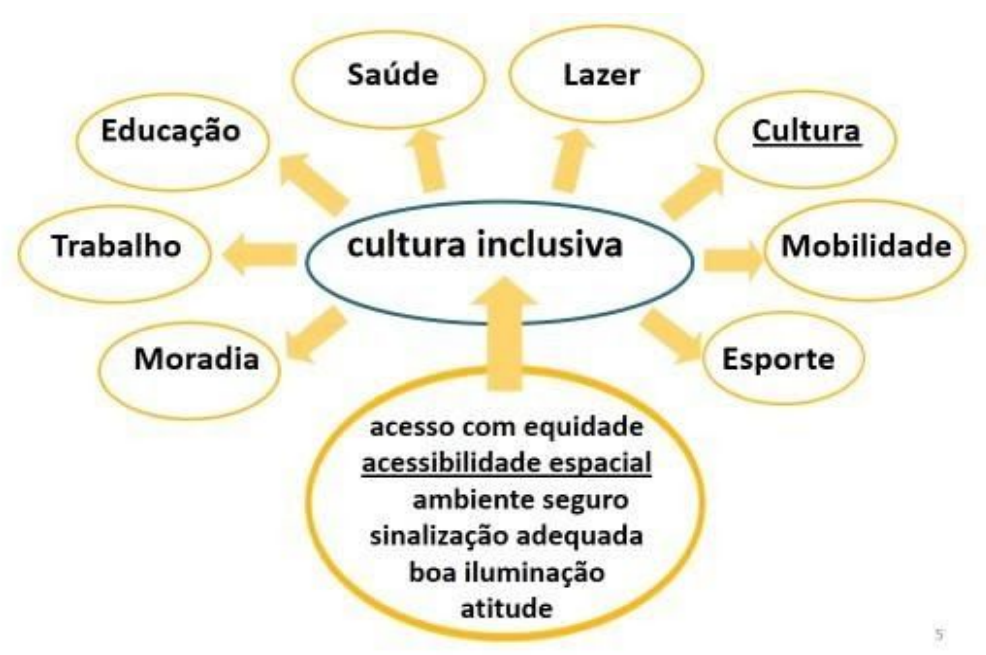

Fonte: autores, 2019

A fim de um maior embasamento, Santos (2009) elenca seis parâmetros para um meio físico acessível:

- Respeitador: deve respeitar a diversidade dos utilizadores, ninguém deve sentir-se marginalizado e a todos deve-se facilitar o acesso;

- Seguro: deve ser isento de risco para todos os utilizadores;

- Saudável: não deve constituir-se em si um risco à saúde;

- Funcional: deve ser desenhado ou concebido para que funcione de forma para que atinja os fins para o qual foi criado;

- Compreensível: todos os usuários devem saber se orientar sem dificuldades, sendo assim necessária uma informação clara; - Estético: o resultado deve ser esteticamente agradável.

Os conceitos citados referem-se às questões relacionadas às pessoas com deficiência, porém, podem ser aplicados dentro da dinâmica entre espaço cultural $x$ frequentador para entender os raios de alcance da palavra acessibilidade, para além das barreiras de desenho projetual. Por meio da lista de parâmetros é possível entender o porquê do esvaziamento desses espaços, consequência de uma dinâmica de opressão social de caráter macro e onipresente.

Segundo Cuty e Couto (2014), referindo-se a políticas públicas no Brasil, comenta que

A nossa curta trajetória em formulações de políticas para a cultura e a forma como estas se sucederam dão conta da fragmentação conceitual e até mesmo da ausência de aporte teórico ao concebê-las, muito em especial no que se refere a sua institucionalização em que a diversidade brasileira muito recentemente foi incorporada. (CUTY; COUTO, 2014, p. 3) 


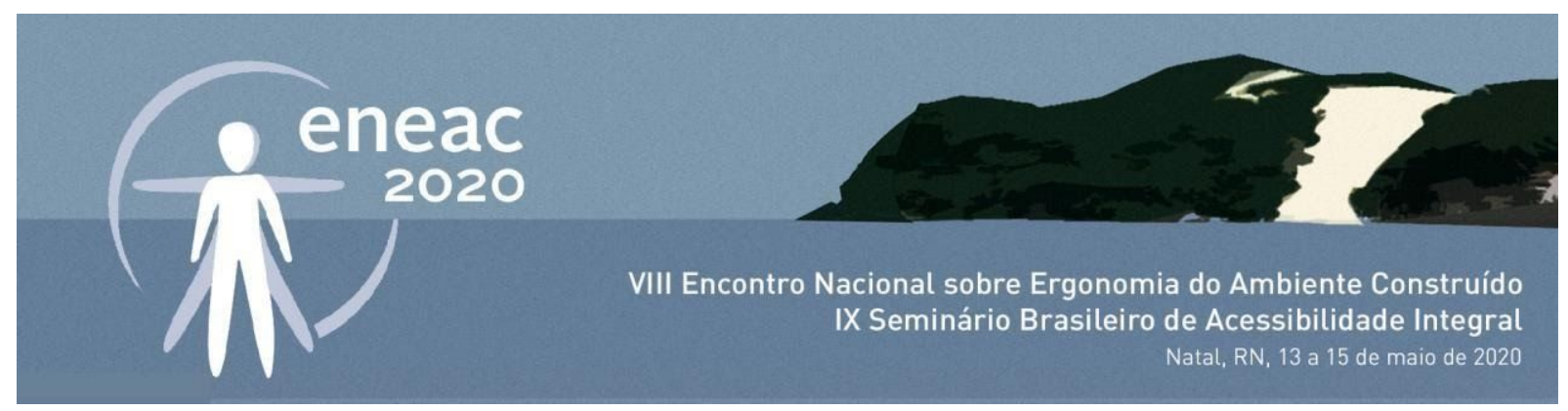

Segundo IPEA, 70\% dos brasileiros nunca foi ao museu ou a um centro cultural, dado que reforça o quanto a arte não é acessível de uma forma geral. Analisando, para além dos parâmetros elencados, fatores como a erudição; o conteúdo produzido para dialogar com a intelectualidade; a produção e consumo desse produto restrita à uma microesfera artística; as tensões territoriais existentes entre equipamentos culturais implantados na cidade formal e aqueles usuários oriundos de parcelas informais; eventual escassez de divulgação e a opressão do Estado para com corpos não padronizados acrescentam-se a lista dos fatores que distanciam a massa social e a arte.

\section{SOBRE O PORTO DRAGÃO}

O Porto Dragão das Artes corresponde a um importante equipamento cultural situado em uma rede de outros equipamentos - como o Instituto Dragão do Mar de Arte e Cultural, a Caixa Cultural, o Teatro São José e o Porto Iracema das Artes - no bairro da praia de Iracema, em Fortaleza. $O$ espaço corresponde a um antigo galpão industrial, que remonta ao processo de ocupação inicial daquele território, que mais tarde foi ressignificado enquanto espaço de arte e cultura com a implementação de uma antiga sede do Sesc Iracema.

Em março de 2018, o espaço que era mantido pela Fecomércio, ao ser fechado, passou a dar lugar ao Porto Dragão, uma mistura de projetos do Porto Iracema das Artes - fundado em 2013 pela Secretaria de Cultura do Estado do Ceará (Secult-Ce) com o Instituto Dragão do Mar (IDM). Foi reinaugurado em abril do mesmo ano, agora com o objetivo de se tornar uma produtora de conteúdo e aceleradora de projetos de culturais em Fortaleza, de modo a ser um espaço de formação e experimentação para uma geração de novos criadores.

O programa de necessidades do Porto Dragão articula-se em dois pavimentos, onde no térreo situam-se: área para exposições temporárias, salão de danças, teatro, cantina/gastrobar, biblioteca e espaço de leitura, salas de aula, bem como porção de serviços (banheiros e manutenção) e núcleo administrativo. Já no andar superior, situam-se mais outras cinco salas de aula/ensaio, bem como uma sala de informática. O espaço - que outrora funcionava como um armazém industrial - passou por uma grande reforma em 2006, e sofreu uma série de outras pequenas intervenções desde então com o intuito de adequá-lo ao seu atual uso. 


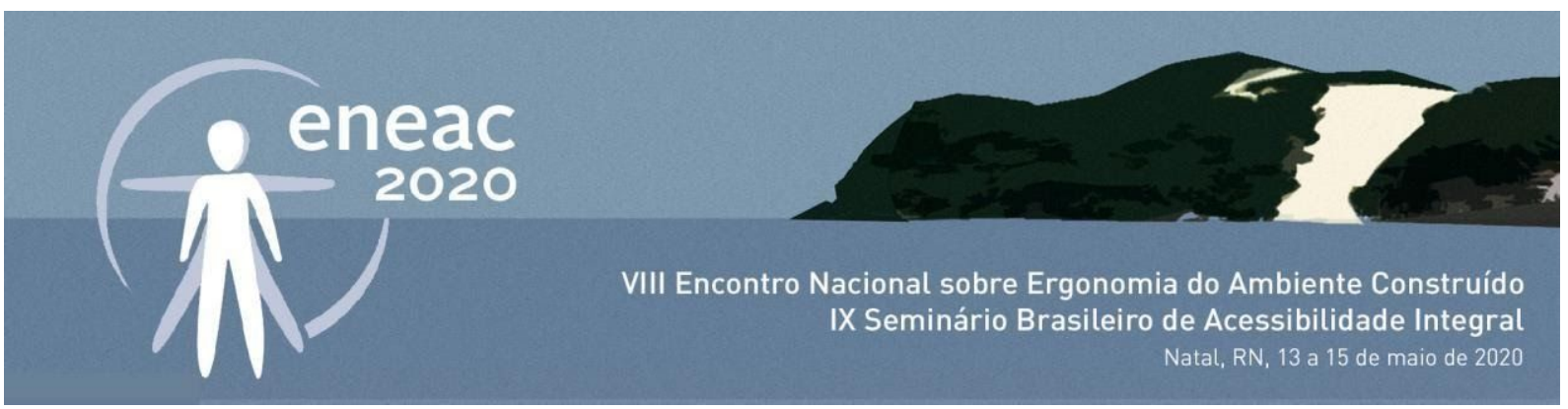

Figura 2: Mapa de localização do Porto Dragão em relação aos demais equipamentos culturais do entorno.

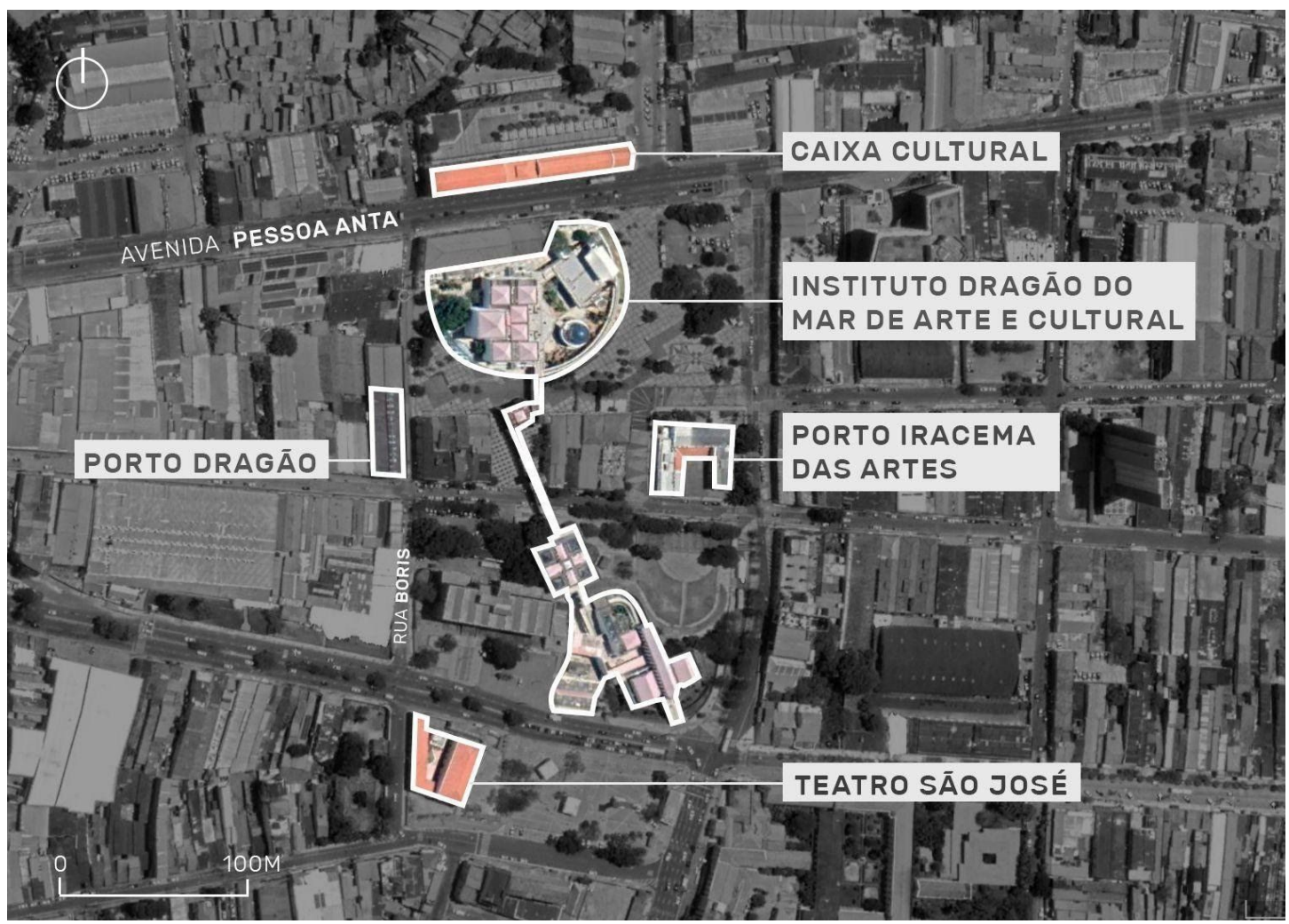

Fonte: Ortofoto Google Earth 2019, modificada pelos autores.

Em dezembro de 2019, o Porto Dragão foi escolhido para sediar o II Seminário Cultura do Acesso, um evento realizado pela Secult-CE com o intuito de provocar agentes dos setores público e privado, bem como da sociedade civil, sobre a inclusão de pessoas com deficiência na cultura, seja como espectadores ou produtores de tais conteúdos. O seminário conta com a participação de professores, cientistas, artistas, produtores e gestores culturais, todos voltados a discutir sobre arte e pessoas com deficiência, suas forças, oportunidades e fraquezas na inserção em um circuito de produção artístico-cultural.

Em virtude deste seminário, era uma oportunidade de o espaço físico do Porto Dragão passar por uma série de pequenas intervenções arquitetônicas e internas com objetivo de garantir o caráter universal ao edifício de acordo com as normas de acessibilidade vigentes - intervenções estas que foram o mote para a produção deste trabalho e serão melhores explicadas a seguir. 


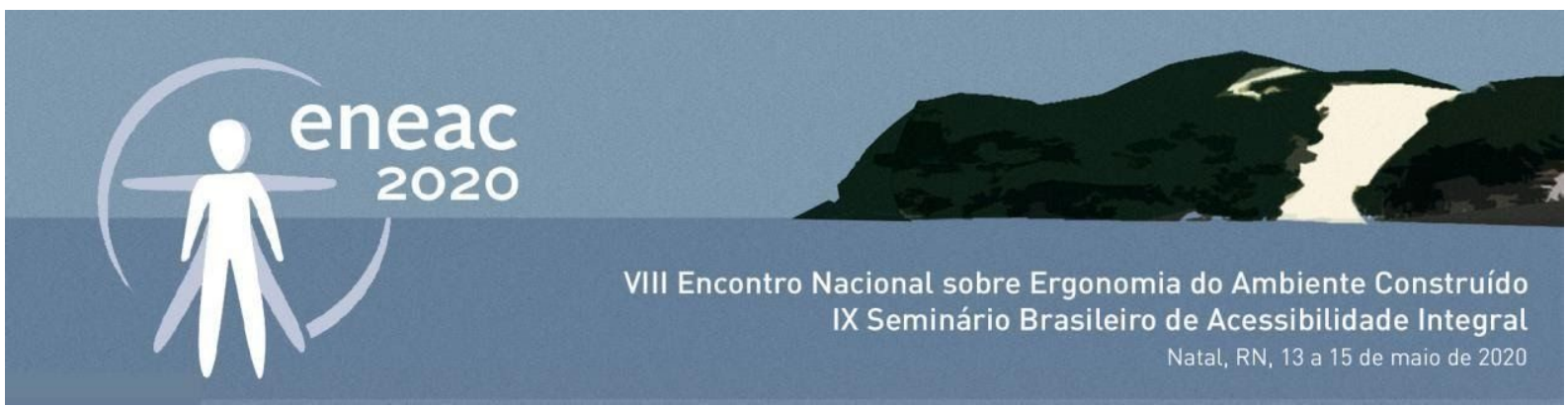

\section{ESTUDO DE CASO: O PORTO DRAGÃO}

\section{Diagnóstico}

Através da visita a campo, pôde-se analisar questões espaciais e de acessibilidade no Porto Dragão; foram observados banheiros, balcões, palco e circulação vertical, além da sinalização para os ambientes, principalmente a sinalização tátil no piso. Desse modo, coletou-se insumos e anotações para estabelecer um diagnóstico da situação da edificação quanto à sua realidade e ao seu potencial acessível.

Percebeu-se que havia tentativas de promover acessibilidade, como a existência de um elevador e de barras de apoio nos banheiros, porém alguns casos, a serem listados a seguir, estavam em desacordo com a NBR 9050:2015 e não cumpriam com a função que pretendiam. A edificação é desprovida de meios que permitam a circulação com autonomia (ou, pelo menos, a identificação dos espaços) por pessoas com deficiência visual (Foto 1). A locomoção dessas pessoas precisaria ser guiada, ou ainda ser colocado o piso tátil e a comunicação em Braille na lateral de cada porta dos diversos ambientes.

No Porto Dragão, existe um palco para apresentações e seu acesso dá-se por uma escadinha de dois degraus, desse modo, não é acessível para cadeirantes; além disso, o palco não possui sinalização de alerta nas suas bordas, o que pode representar um risco para deficientes visuais (Fotos 2 e 3).

Foto 1: Circulação

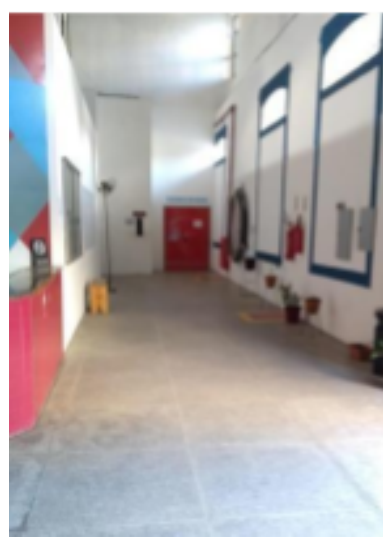

Fotos 2 e 3: Circulação e palco

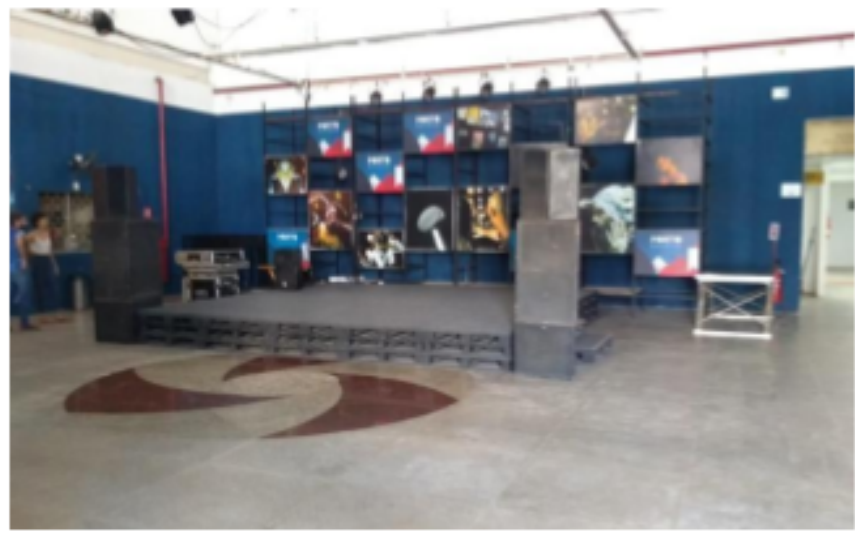

Fonte: Acervo Pesquisa, 2019

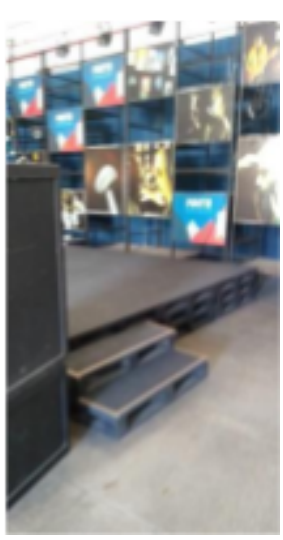

Dos balcões de atendimento, existem quatro no Porto Dragão: um da recepção (Fotos 4 e 5), um da bilheteria (Foto 6) e dois da cantina (Foto 7). Nenhum dos balcões possui rebaixamento que possibilite atender pessoas em cadeira de rodas ou de baixa estatura. 


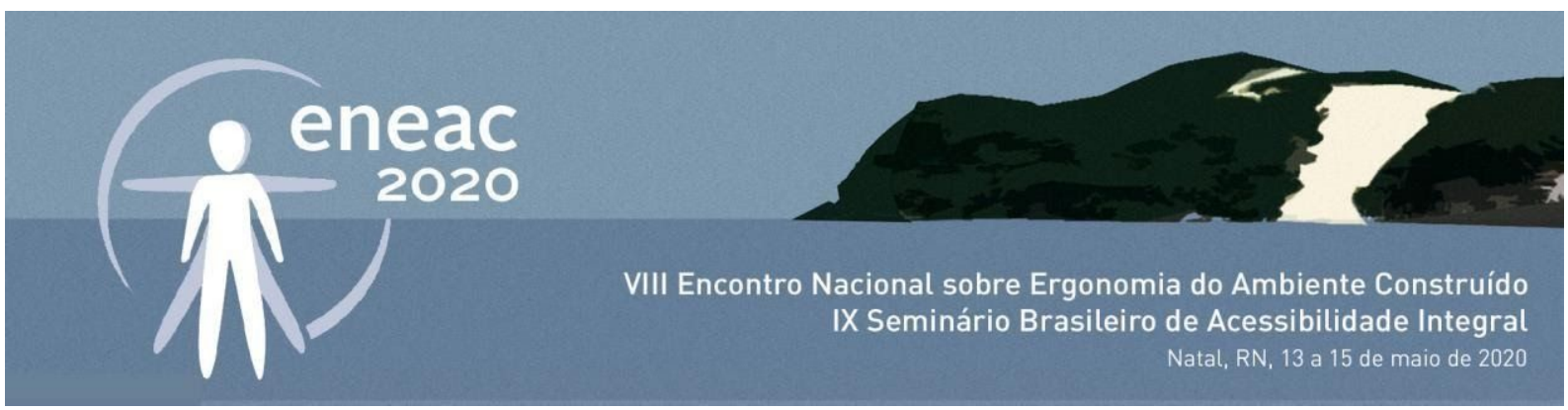

Fotos 4 e 5: balcão da recepção

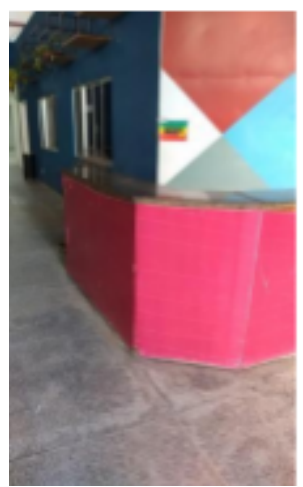

Foto 6: bilheteria do teatro

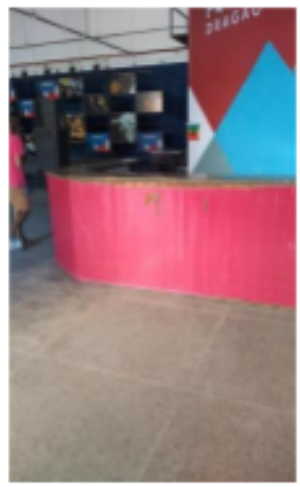

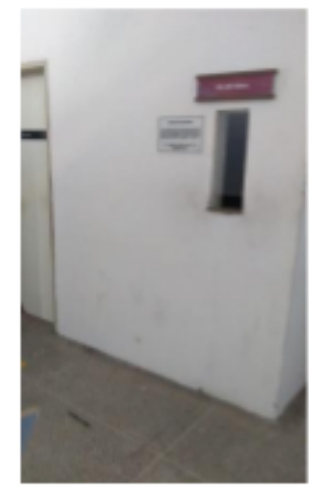

Foto 7: balcões da cantina

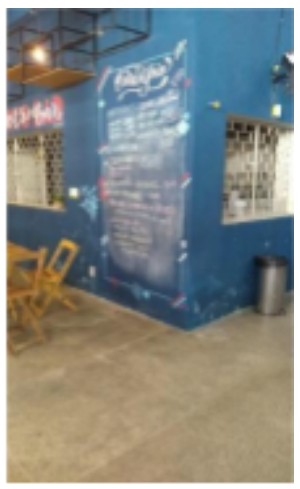

Fonte: Acervo Pesquisa, 2019

Os sanitários de uso público possuem um bom potencial para acessibilidade, devido à área disponível e à bancada de lavatórios (Foto 8), que possui uma parte rebaixada (as pias contam com torneiras de válvulas de pressão). Existem cabines acessíveis, porém não se encontram totalmente adequadas; no sanitário masculino, a largura da cabine é de $1,30 \mathrm{~m}$, e no feminino (Foto 9) é de 1,25m (enquanto a Norma exige 1,50m, no mínimo), além disso, as barras de apoio que existem não estão dispostas adequadamente. As cabines dos chuveiros são estreitas e não possuem banco, portanto não atendem usuários em cadeira de rodas; em uma delas, do sanitário masculino (Foto 10), há barras de apoio, porém inadequadas. Espelho e acessórios sanitários também não estão acessíveis para cadeirantes (Foto 8). E um outro ponto notado foi a porta do sanitário masculino (Foto 11), que não é adequada por possuir mola e, por isso, dificultar o acesso.

Fotos 8 e 9: Bancada e box acessível sanitário feminino

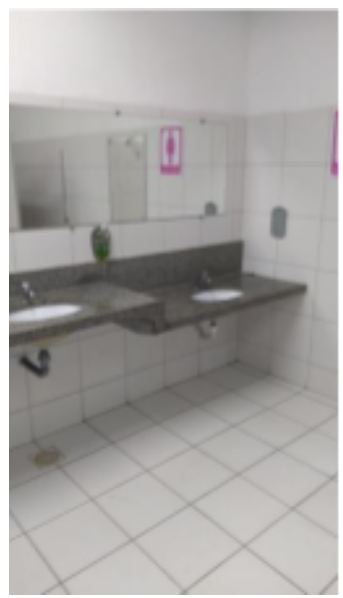

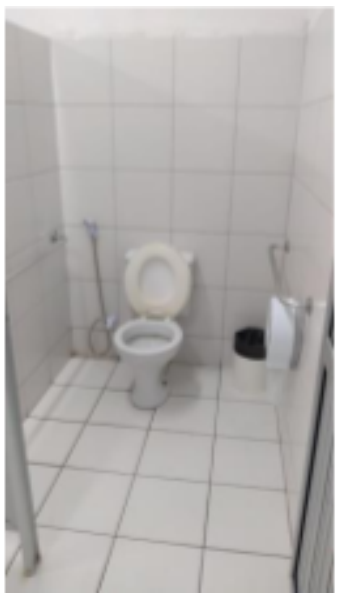

Fotos 10 e 11: Chuveiro e porta sanitário masculino
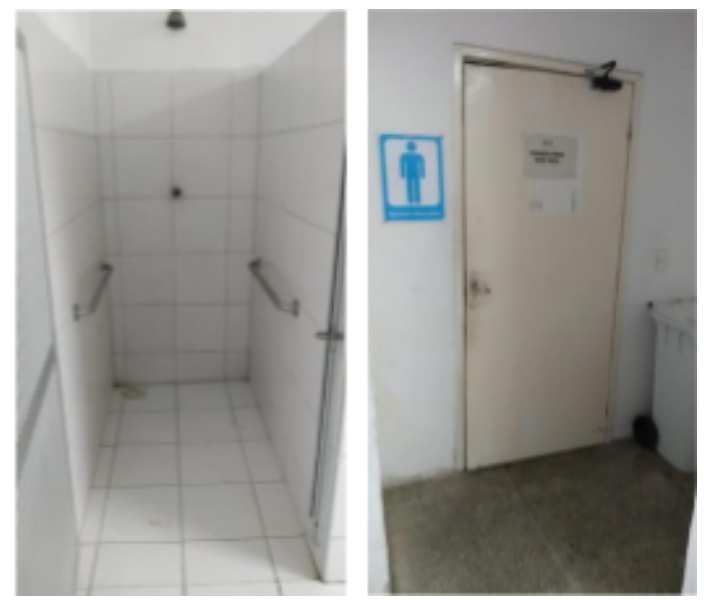

Fonte: Acervo da Pesquisa, 2019 


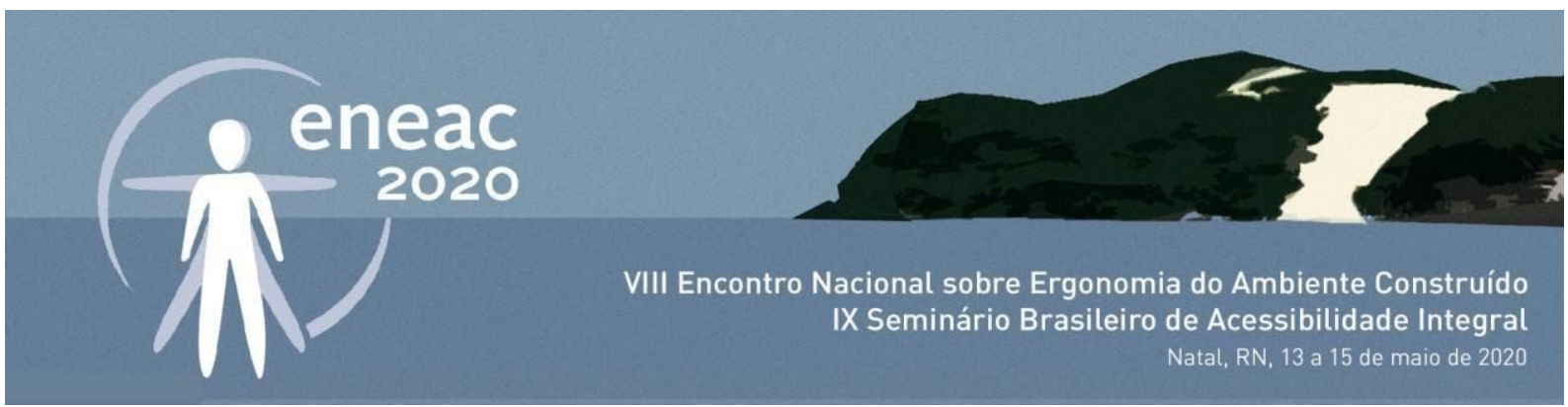

Para o teatro do Porto Dragão, há dois camarins, ambos com banheiro (chamados aqui de $\mathrm{A} e$ B). Em um deles, a porta é de correr e existem duas barras de apoio instaladas (Fotos 13, $14 \mathrm{e}$ 15), entretanto, possui muitos desacordos com a Norma, não podendo ser considerado acessível. Tais erros são: barras de apoio inadequadas para a situação da bacia sanitária, lavatório de coluna, porta de vidro para o boxe do chuveiro, ausência de área útil interna para giro de $360^{\circ}$, além de outros relacionados aos acessórios sanitários.
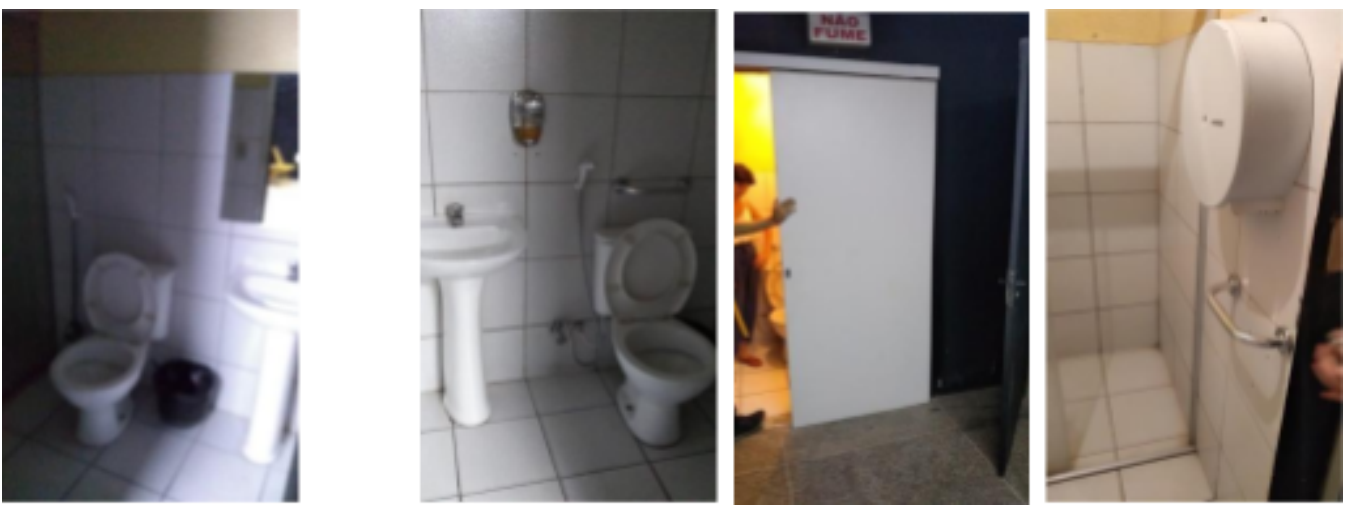

Fonte: Acervo Pesquisa, 2019

A edificação, de dois pavimentos, conta com uma escada (Foto 16) de estrutura em peças metálicas, vigamento em perfil I, guarda-corpo trabalhado em trama de aço e degraus em madeira. Espelho vazado. Possui 29 metros de extensão e 29 degraus (piso $=0,28 \mathrm{~m}$ e espelho=0,16m). Não está em conformidade com as recomendações da NBR 9050 para escada de uso público/coletivo. Depois, foi adicionado um elevador (Foto 17) conectando os pisos térreo e superior, com medidas que comportam a entrada de uma cadeira de rodas. A escada não está de acordo com a Norma, pois não possui patamar, fechamentos nos espelhos nem corrimão duplo.
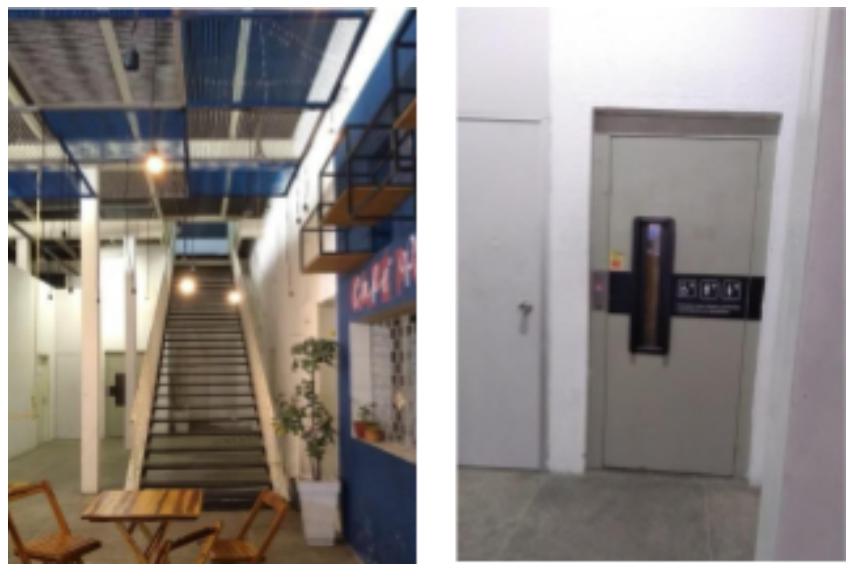

Fonte: Acervo da pesquisa, 2019 

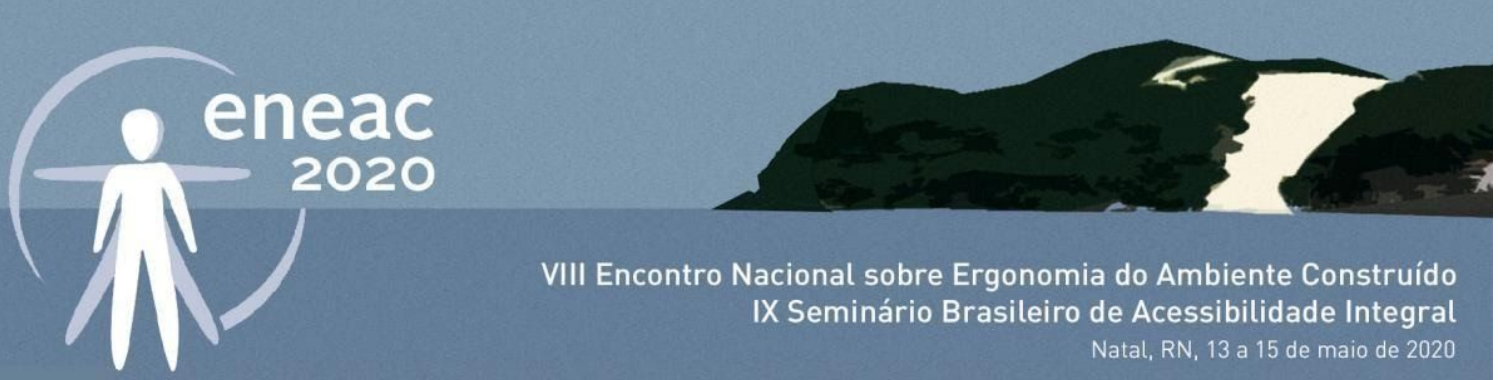

VIII Encontro Nacional sobre Ergonomia do Ambiente Construído

IX Seminário Brasileiro de Acessibilidade Integral

Natal, RN, 13 a 15 de maio de 2020

Diante dos dados coletados, pode-se dizer que a acessibilidade do Porto Dragão é insuficiente e incompleta. Tal situação é agravada quando se expande essa análise para considerações externas, ou seja, aspectos urbanos que influenciam o uso da edificação (calçadas e seus revestimentos, acessos, travessias, vagas de estacionamento), que não serão analisados neste trabalho. Para contribuir com o debate e reflexões sobre a acessibilidade em equipamentos culturais, desenvolveu-se um conjunto de propostas.

\section{Requisitos de um equipamento cultural acessível}

Em função da demanda de adequação para melhor receber o público do II Seminário Cultura do Acesso no Porto Dragão, o GT Cultura do Acesso, juntamente com alunos da Disciplina de Desenho Universal do curso de Arquitetura e Urbanismo da Universidade Federal do Ceará (UFC) trabalharam no sentido de além de fazer um diagnóstico, que contou com participantes do GT, incluindo pessoas com deficiência visual, propor algumas adequações para o espaço interno do Porto Dragão (Figura 3).

Figura 3: Planta do Porto Dragão e pontos a serem trabalhados na adequação.

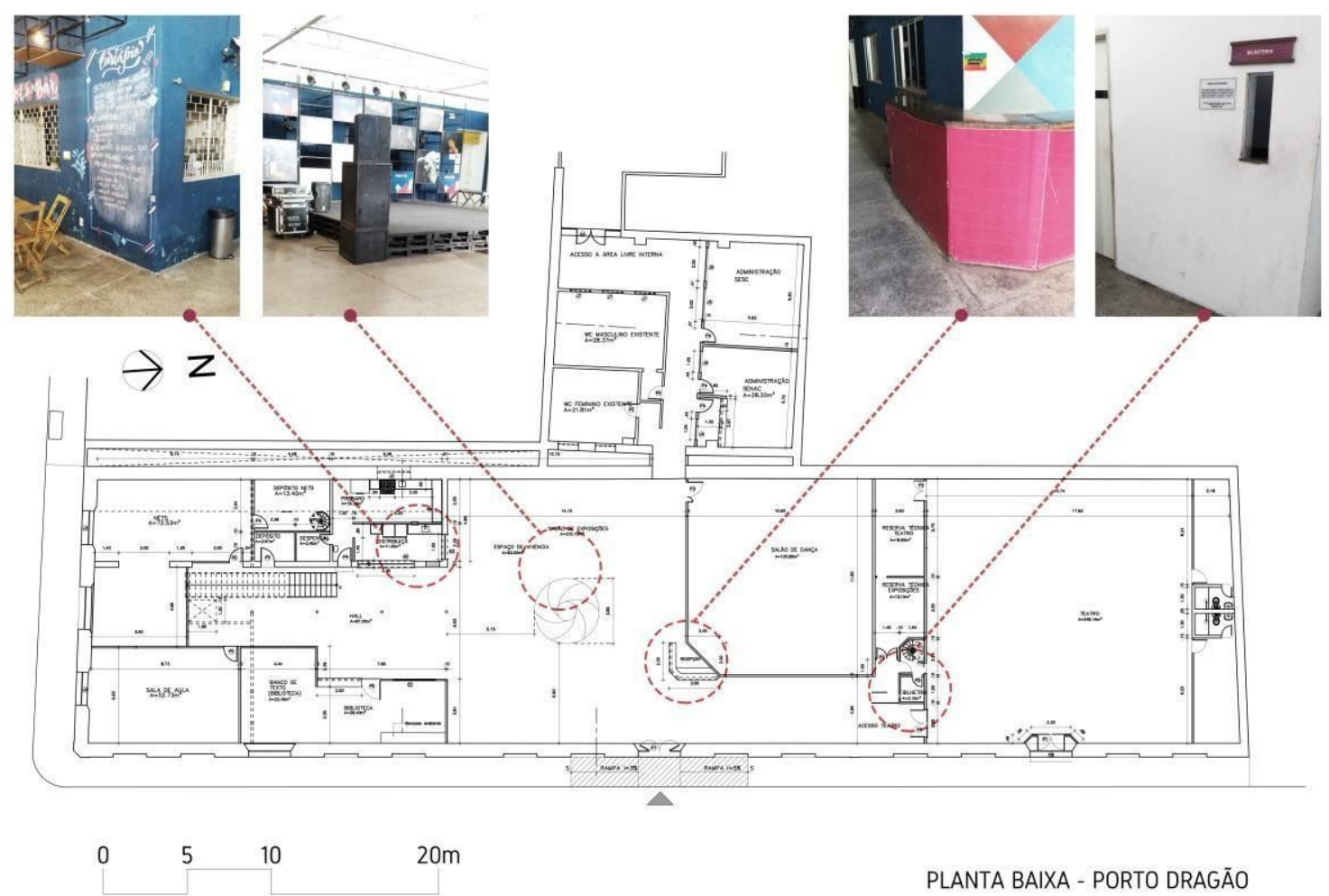

Fonte: Planta cedida pela Secult, modificada pelos autores, 2019

Além das adequações previstas conforme a Figura 3, foi implantado o piso tátil interno e proposto o mapa tátil, que ainda se encontra em discussão sobre os dispositivos e materiais empregados para sua melhor forma de atendimento às pessoas com deficiência visual. 

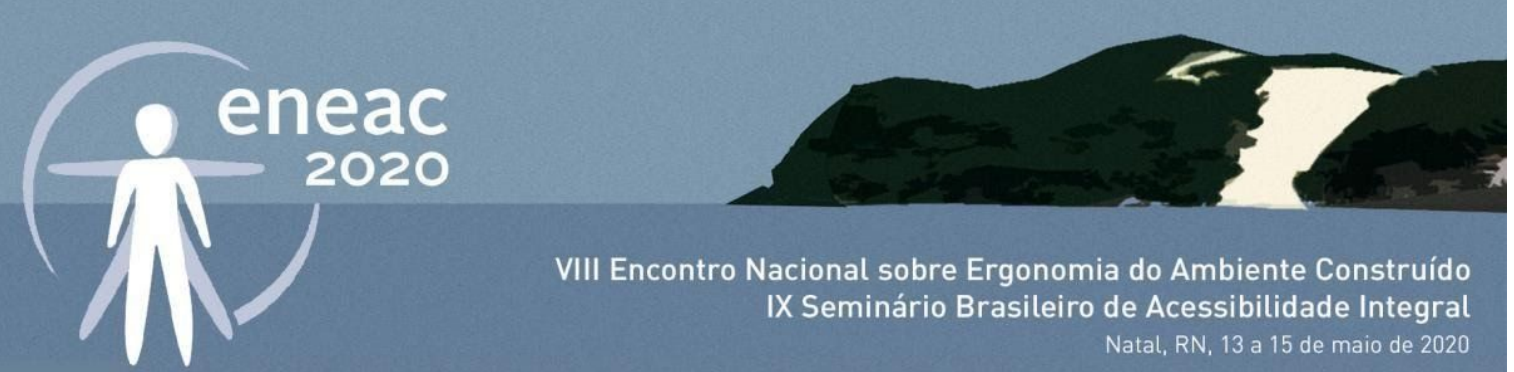

VIII Encontro Nacional sobre Ergonomia do Ambiente Construído

IX Seminário Brasileiro de Acessibilidade Integral

Natal, RN, 13 a 15 de maio de 2020

\section{Aplicação do piso tátil (direcional e alerta)}

A proposta do piso tátil (Figuras 4 e 5) foi de propiciar o alcance de todos os ambientes e principais pontos do espaço livre interno com autonomia e segurança para pessoas com deficiência visual, contando com a posição do mapa tátil na entrada da edificação.

Figuras 4 e 5: Proposta de piso tátil/alerta a ser adequado na reforma.

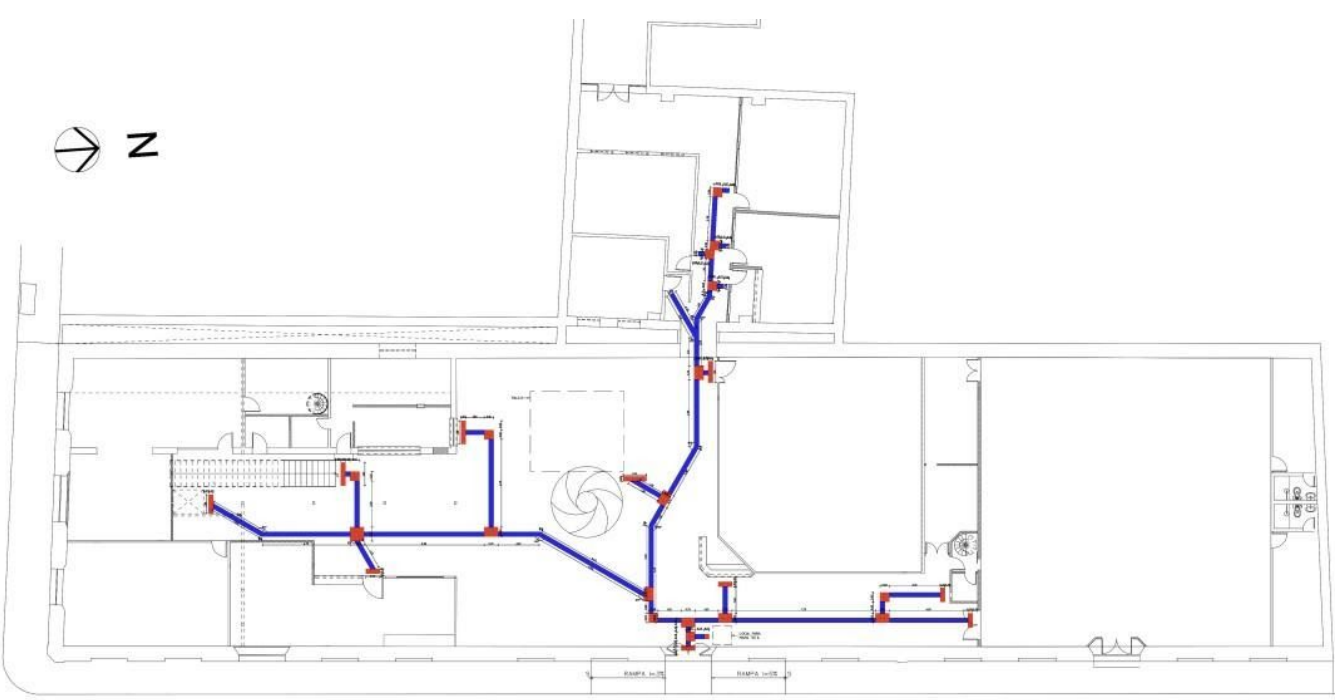

$\begin{array}{llll}0 & 5 & 10 & 20 \mathrm{~m}\end{array}$

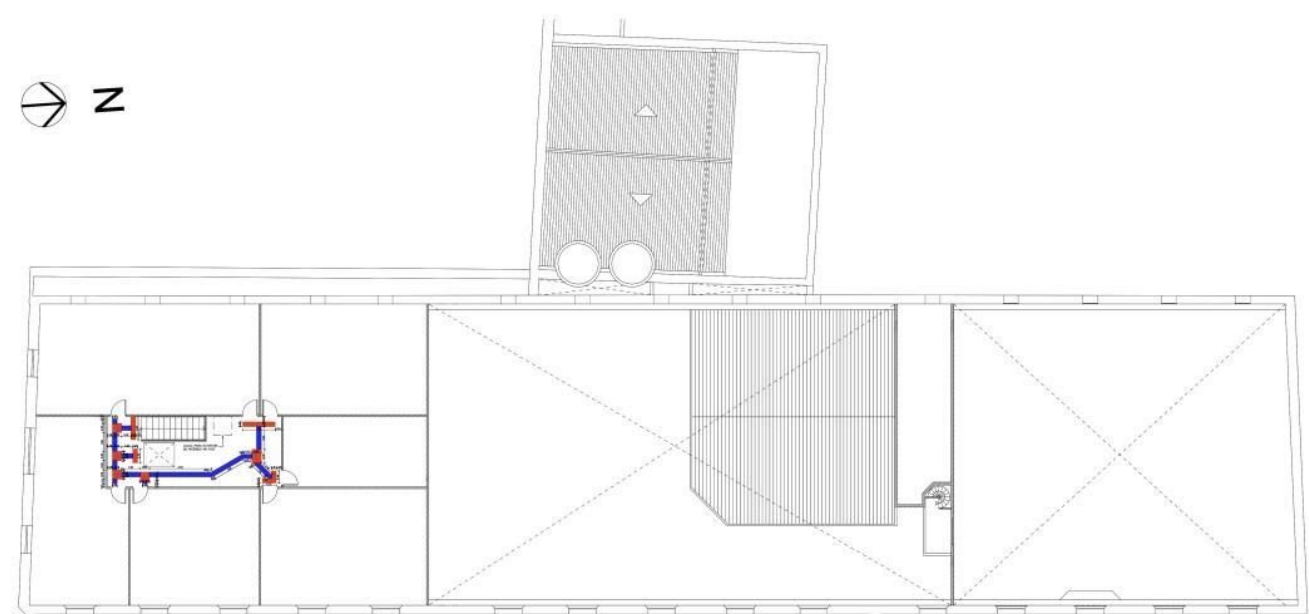

\begin{tabular}{llll}
$0 \quad 5 \quad 20 m \quad 20$ & LEGENDA: \\
\hline & & PISO TÁTIL DIRECIONAL
\end{tabular}

PAGINAÇĀO PISO TÁTIL - PVTO SUPERIOR 


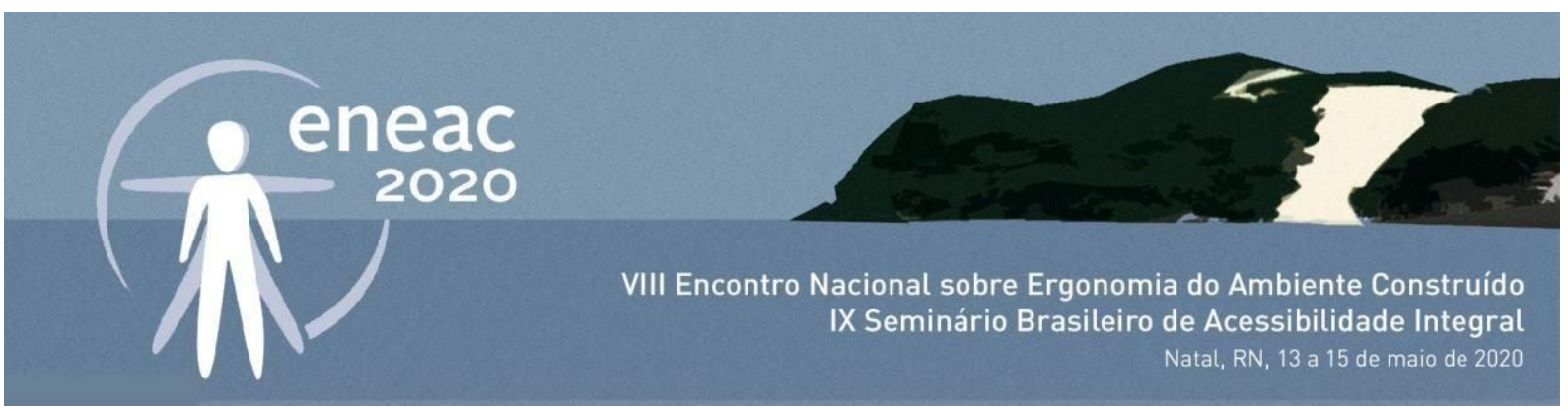

Fonte: Planta cedida pela Secult, proposta elaborada pelos autores.

\section{Balcão da recepção}

Como apresentado no diagnóstico, este balcão não possui condições adequadas para atender usuários de cadeira de rodas ou pessoa de baixa estatura. A proposta (Figuras 6 e 7) foi trabalhar uma parte da bancada rebaixada, conforme as recomendações da NBR 9050:2015, nisso atende tanto para um recepcionista como para o público a ser atendido.

Figura 6: Proposta de adequação para balcão recepção

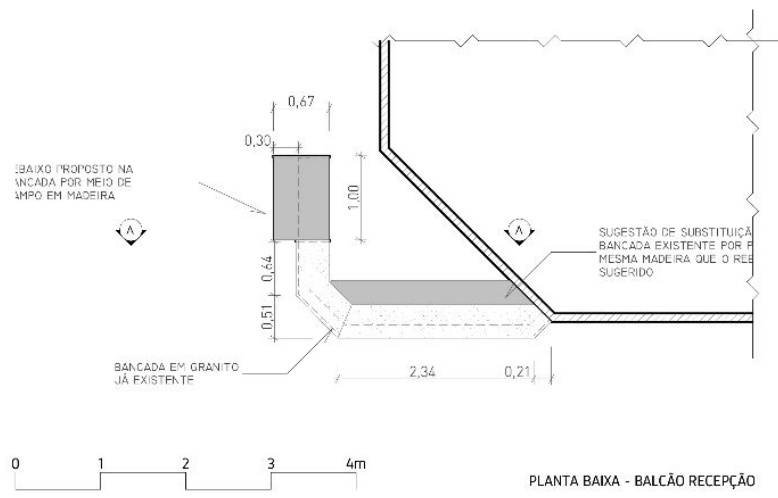

Figura 7: Foto balcão após reforma

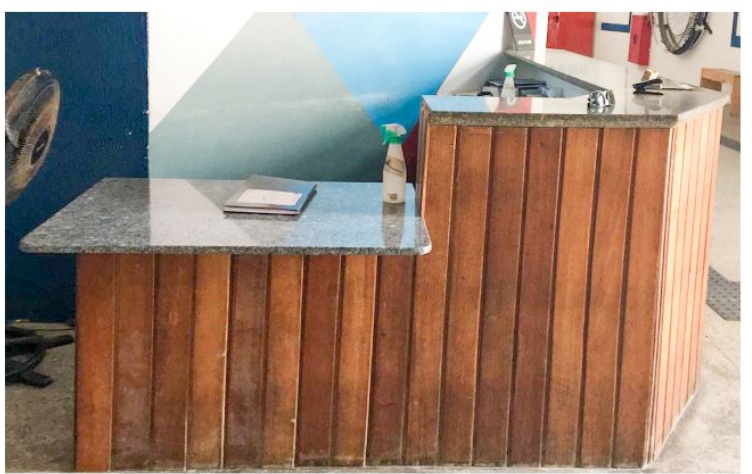

Fonte: Acervo da pesquisa, 2019

\section{Palco}

Resolvendo a falta de acessibilidade do palco por cadeirantes, foi proposto uma rampa móvel (Figuras 8 e 9), que possui uma estrutura leve e piso antiderrapante. Também foi pensando na sinalização de alerta nas bordas do palco para orientar deficientes visuais.

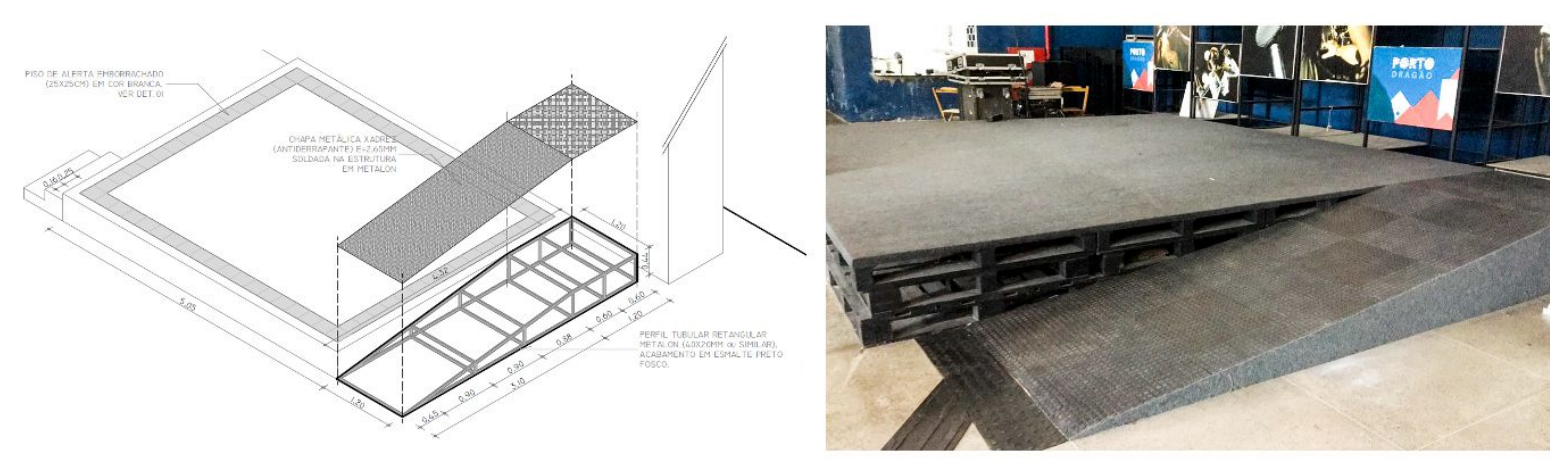




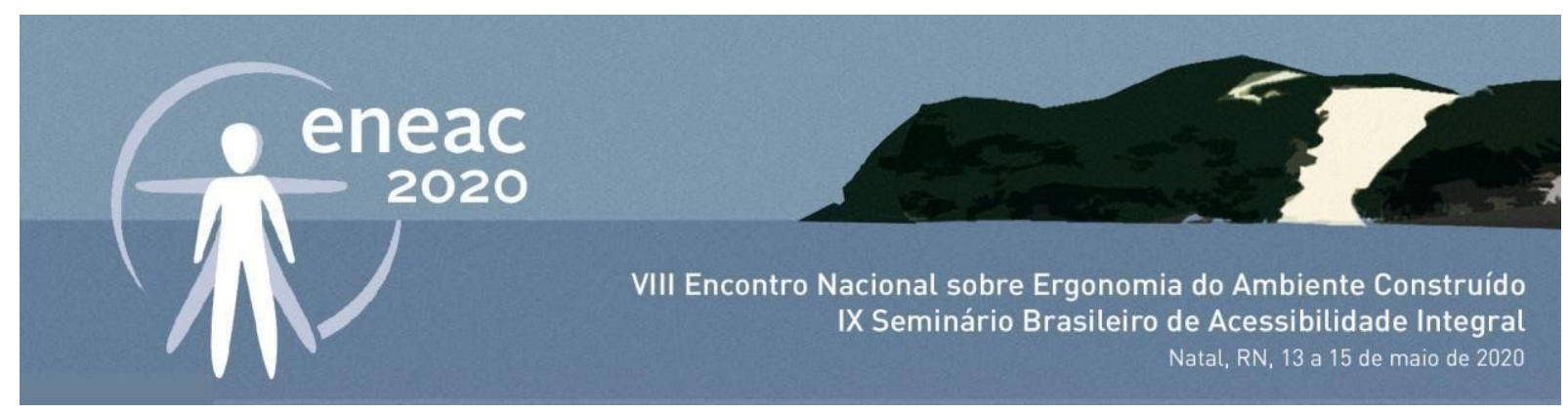

\section{Balcão da cantina}

Dos balcões de atendimento da cantina, foi proposto, para um deles, o rebaixamento e colocação de uma pedra com área de aproximação (Figuras 10 e 11), conforme recomenda a NBR9050:2015, de forma a possibilitar atender pessoas em cadeira de rodas ou de baixa estatura.
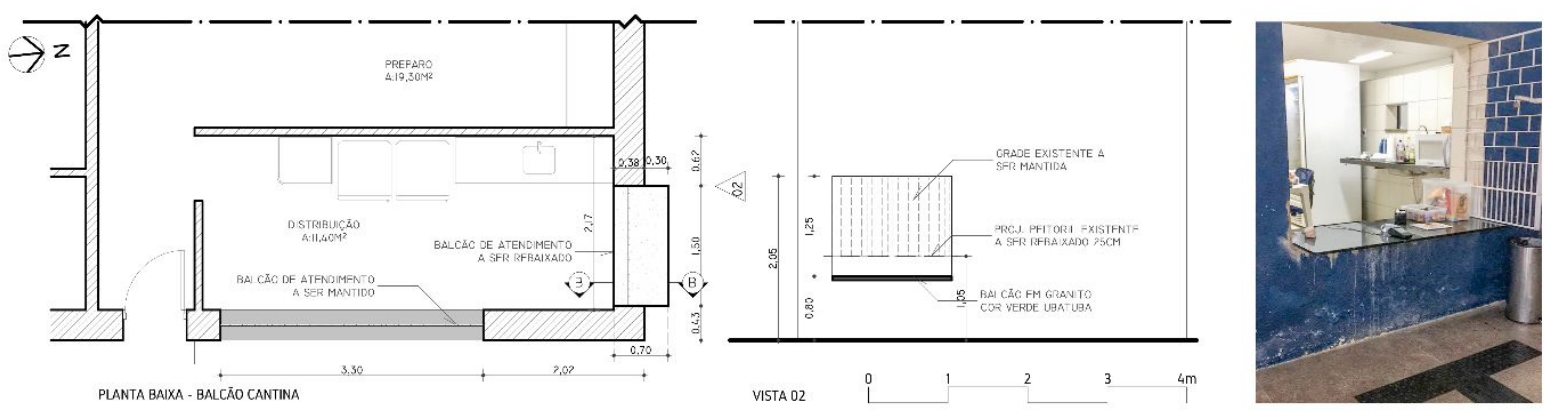

Fonte: Acervo da pesquisa, 2019

\section{Bilheteria do teatro}

A bilheteria existente se apresenta alta e sem acesso adequado a pessoa com baixa estatura ou usuário de cadeira de rodas; então, foi proposto um rebaixamento e um balcão com área de aproximação (Figuras 12, 13 e 14).

Figuras 12, 13: proposta de reforma para o balcão da bilheteria.

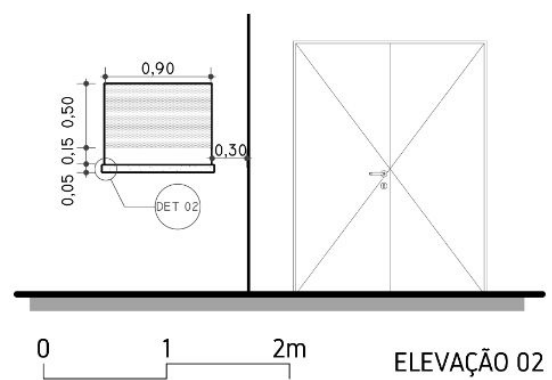

Figura 14: Foto balcão da bilheteria após reforma.

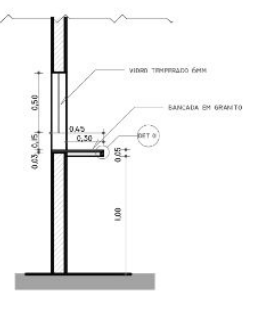

CORTE AA'

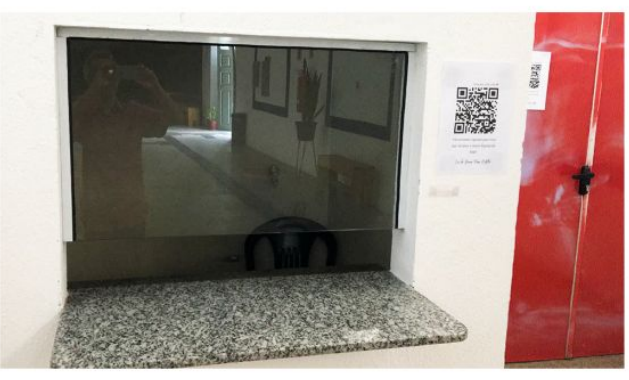

Fonte: Acervo da pesquisa, 2019 


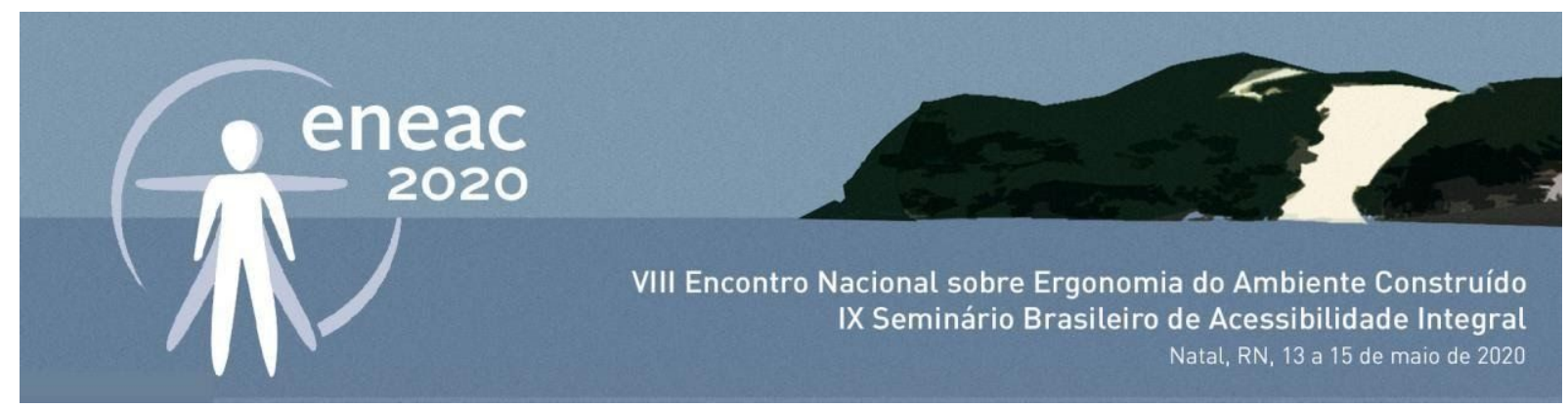

\section{Escada}

Como elemento de circulação vertical, além do elevador, foi proposto para a escada a instalação dos corrimãos em ambos os lados, a 0,92 $\mathrm{m}$ e a 0,70 $\mathrm{m}$ do piso, tendo continuado o espelho vazado, que em outra ocasião pode vir a ser modificado de forma regulamentar com as recomendações da NBR 9050 para escada de uso público/coletivo.

Figura 15: Foto da escada após reforma.

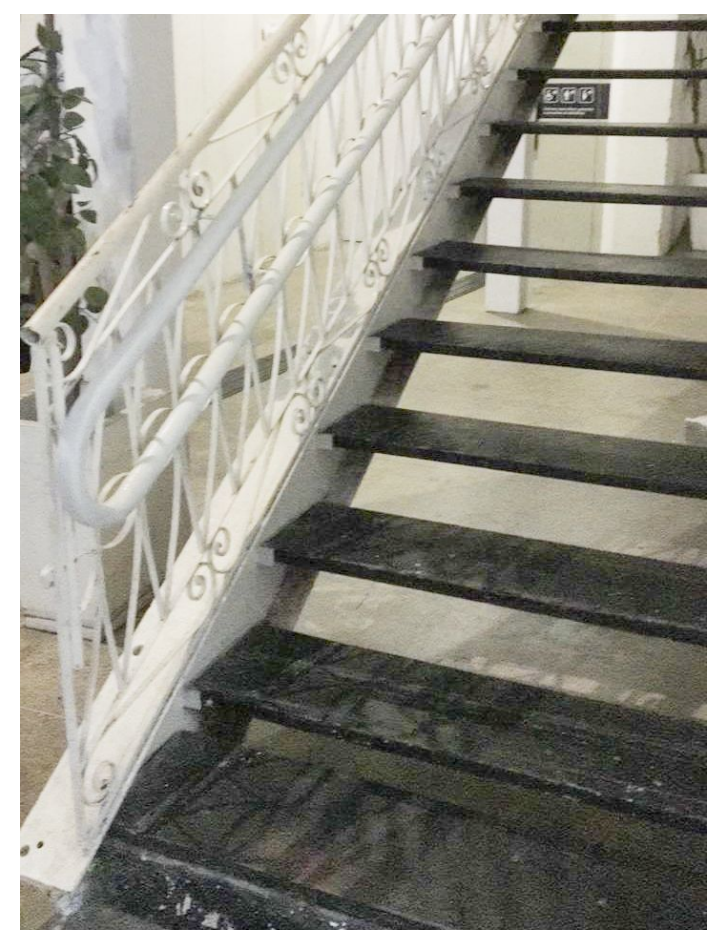

Fonte: Acervo da pesquisa, 2019

As demais adequações se fizeram por recomendações para uma próxima reforma, visto que, para sediar o II Seminário de Cultura do Acesso, foram atendidas as propostas aqui definidas. Assim, os banheiros não foram contemplados nesta ocasião, por se tratar de uma mudança mais radical em alguns pontos e necessidade de verba e tempo. É nesta linha que insistimos em repetir Ponte (2015) quando afirma que "as barreiras atitudinais não são visíveis como as barreiras físicas, na maioria das vezes, são inconscientes e de difícil reconhecimento por parte de quem as pratica". Contudo, muitas vezes são as barreiras atitudinais que dificultam ou impedem a eliminação das barreiras físicas. 


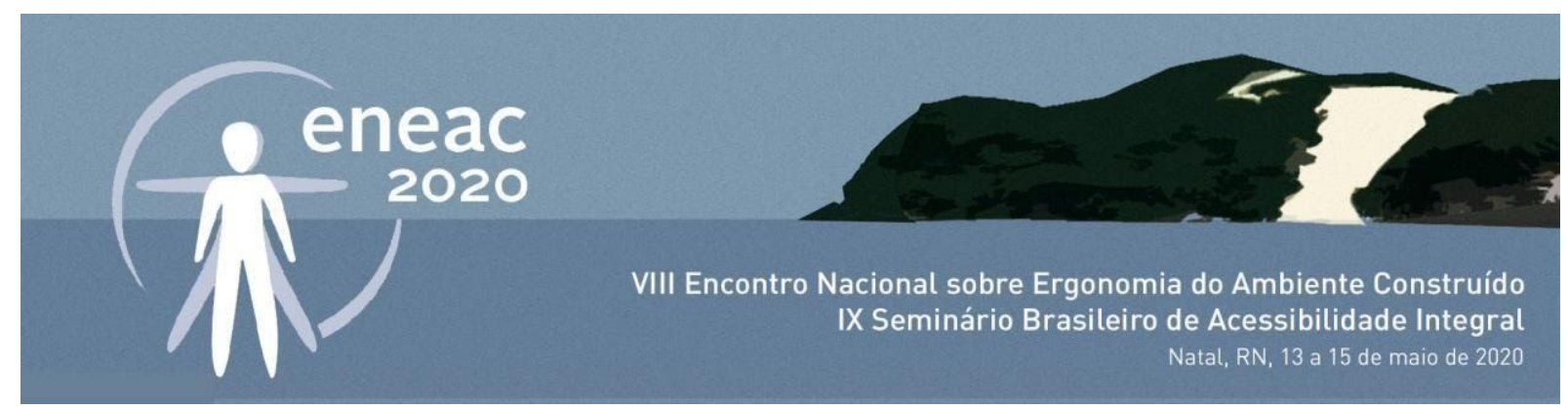

\section{CONCLUSÃO}

Após uma sensibilização inicial sobre a relação entre acessibilidade e equipamentos culturais, jogando luz sobre as diversas facetas de entraves existentes para se democratizar o acesso à cultura e a arte, ficou claro a potencialidade de extensão da análise das diversas motivações para o não acesso a cultura. Porém, assumindo os limites da área de alcance que a arquitetura e urbanismo têm a capacidade de atuar para solucionar questões de segregação espacial e cultural, optou-se, neste artigo, a restringir-se às ações de intervenção ao ambiente construído.

Portanto, através do estudo de caso do Porto Dragão, um equipamento de uso atual, porém instalado em uma edificação que outrora foi concebida para outros fins, isto é, galpões da antiga área de armazéns do Porto, entende-se uma eventual dificuldade no processo de adaptação à acessibilidade. Convém destacar, também, as dificuldades advindas da própria natureza da demanda, que por adotar um caráter paliativo e emergencialista, acabou por atropelar algumas etapas do processo de projeto que seriam necessárias para completa análise e proposição do espaço em sua plena condição de acessibilidade. Além disso, também surgiram algumas restrições de natureza orçamentária, devendo as intervenções propostas serem de fácil exequibilidade, sem grandes alterações na estrutura e instalações pré-existentes no espaço.

Por fim, ao se analisar de maneira mais ampla, é possível destacar uma repetição de padrão entre as edificações de mesmo uso distribuídas ao redor do Porto Dragão, centros culturais instalados em edifícios antigos, com exceção do Dragão do Mar e do Porto Iracema das artes, equipamentos culturais construídos pós anos 2000. Para contornar as limitações de acessibilidade oriundas de outro cenário histórico no qual esses edifícios foram levantados, observa-se uma iniciativa de adequação às normas de acessibilidade, contudo não realizada de forma plena, tornando a edificação apenas potencialmente acessível. Energia e capital são gastos para uma não resolução de problema.

\section{REFERÊNCIAS}

ASSOCIAÇÃO BRASILEIRA DE NORMAS TÉCNICAS. ABNT NBR 9050. Acessibilidade e edificações, mobiliário, espaços e equipamentos urbanos. Rio de Janeiro. 2015.

ASSOCIAÇÃO BRASILEIRA DE NORMAS TÉCNICAS. ABNT NBR 16.537. Acessibilidade - Sinalização tátil no piso - Diretrizes para elaboração de projetos e instalação. Rio de Janeiro. 2016.

CARDOSO, Eduardo; CUTY, Jeniffer. Recursos de acessibilidade em ambientes culturais: contextualização e aplicações. Porto Alegre: Marco Visual, 2012.

CORDEIRO, Mauro. PORTO DRAGÃO: um novo teatro, espaço de ensaio e criação para a cidade. Disponível em <http://www.tribunadoceara.com.br/blogs/dialogos-urbanos/cultura/porto-dragao-um-novo-teatro-espa co-deensaio-e-criacao-para-cidade/> Acesso: Dez, 2019

CUTY, Jeniffer; COUTO, Doris. Acessibilidade Cultural: respeito à multiplicidade e à singularidade do humano como pressupostos para viabilidade. De Um Museu Para Todos In: Anais do V SEMINÁRIO INTERNACIONAL - POLÍTICAS CULTURAIS - Setor de Políticas Culturais - Fundação Casa de Rui Barbosa - Rio de Janeiro - Brasil, 2014.

DISCHINGER, Marta, ELY, Vera H. M. B.; PIARDI, Sônia M. D. G.. Promovendo acessibilidade espacial nos edifícios públicos. Programa de Acessibilidade às Pessoas com Deficiência ou Mobilidade Reduzida nas Edificações de Uso Público. MPSC Ministério Público de Santa Catarina. Florianópolis - SC, Brasil - 1a Edição - 2014 


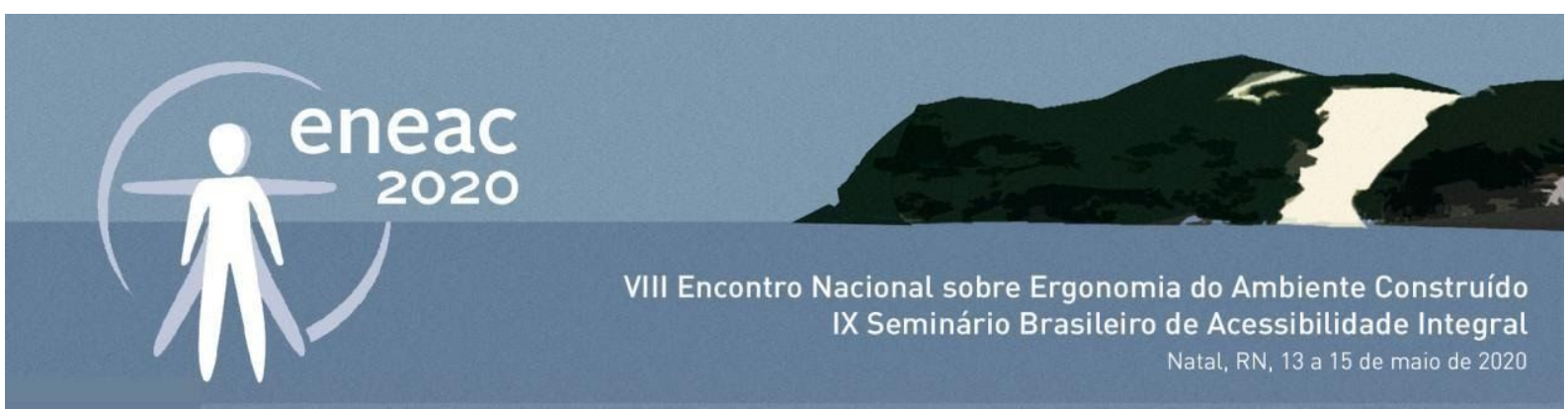

PORTO IRACEMA DAS ARTES. Histórico. Disponível em <http://www.portoiracemadasartes.org.br/a-escola/historico/>. Acesso: Dez, 2019.

SANTIAGO, Zilsa Maria Pinto; NASCIMENTO, Raquel Martins do; SALES, Fernanda Rocha. Acessibilidade em edifícios públicos: estudo de caso - instituto de educação física e esportes no Campus do Pici - UFC. In: Anais do VI Encontro Nacional de Ergonomia do Ambiente Construído (ENEAC), Recife, 2014.

SANTOS, Sônia Maria Almeida. Acessibilidade em museus. Dissertação de Mestrado - Curso integrado de estudos pós-graduados em museologia. Porto: Faculdade de Letras da Universidade do Porto, 2009.

SANTOS FILHO, Gildo Magalhães. Construindo um itinerário histórico do desenho universal: a normatização nacional e internacional da acessibilidade. In: ORNSTEIN, Sheila Walbe; ALMEIDA PRADO, Adriana Romeiro de; LOPES, Maria Elisabete (orgs.) Desenho Universal: caminhos da acessibilidade no Brasil. São Paulo, Annablume, 2010. p. 35 - 43.

SARRAF, Viviane Panelli. Acessibilidade cultural para pessoas com deficiência - benefícios para todos. In: Revista do Centro de Pesquisa e Formação / № 6, junho 2018. PP. 23-43. 